\title{
Intracerebral Hemorrhage: A Brief Evidence- Based Review of Common Etiologies, Mechanisms of Secondary Injury, and Medical and Surgical Management
}

\author{
Anand K. Sarma ${ }^{1}$ Shivani Ghoshal ${ }^{1} \quad$ Spencer J. Craven ${ }^{2} \quad$ Aarti Sarwal $^{1}$
}

${ }^{1}$ Division of Neurocritical Care, Department of Neurology, Wake
Forest Baptist Health, Medical Center Boulevard, Winston-Salem,
North Carolina, United States
2Department of Neurology, Wake Forest Baptist Health, Medical
Center Boulevard, Winston-Salem, North Carolina, United States

J Neuroanaesthesiol Crit Care 2019;6:119-130

\begin{abstract}
Address for correspondence Anand K. Sarma, MD, Division of Neurocritical Care, Department of Neurology, Wake Forest Baptist Health, Medical Center Boulevard, Winston Salem, NC 27157, United States (e-mail: asarma@wakehealth.edu).
\end{abstract}

\begin{abstract}
Keywords

- coagulopathy reversal

- intracerebral hemorrhage

- management

- minimally invasive

- perihematomal edema

Intracerebral hemorrhage (ICH) accounts for only 10 to $15 \%$ of all strokes but remains a significant cause of morbidity and mortality. Despite lengthy stays in critical care units, only one-half of those experiencing an ICH survive after 30 days, and those who do are often left with considerable disability. Treatment has traditionally focused on minimizing the hemorrhage expansion and reducing clot volume through both medical and surgical means. Management of $\mathrm{ICH}$ is a complex and multidisciplinary process. This review will discuss a few common etiologies, explore the pathophysiology of secondary neuronal injury after $\mathrm{ICH}$, review the basics of $\mathrm{ICH}$ imaging with computed tomography and magnetic resonance imaging, and highlight latest practices in medical and surgical management. Secondary injury mechanisms such as perihematomal edema and disordered cerebral autoregulation are discussed as potential targets for new treatment modalities. Emergent treatment in the "golden hour" after ictus provides a template of measures to adopt from initial contact with emergency medical services, to the emergency department, and thereafter, triage to the intensive care unit. Medical management including blood pressure control, hemostasis, and coagulopathy reversal are discussed and evidence from trials such as INTERACT 2, ATACH 2, and ANNEXA-4 are given a clinical context. Surgical management including intracranial pressure monitoring, surgical evacuation with open craniotomy, and minimally invasive approaches such as stereotactic-guided aspiration and thrombolysis, ultrasound-induced thrombolysis, image-guided stereotactic endoscopic aspiration, and stereotactic ICH underwater blood aspiration are enumerated. The outcomes and relevance of STICH, MISTIE, and CLEAR trials to present surgical care are elaborated. The review summarizes the current guidelines for the treatment of $\mathrm{ICH}$ and the latest literature in the field they are based upon. It aims to provide a concise article beneficial to the emergency physicians and neurointensivists/neuroanesthesiologists.
\end{abstract}

\section{Introduction}

Although intracerebral hemorrhage (ICH) accounts for only 10 to $15 \%$ of all strokes, it remains a significant cause of morbidity and mortality, with severe long-term disability. The prevalence of ICH is increasing, particularly in developing countries, exacerbated by increases in hypertension (HTN), received

January 31, 2019

accepted after revision

April 15, 2019
DOI https://doi.org/

$10.1055 / \mathrm{s}-0039-1689740$

ISSN 2348-0548.
Copyright $\odot 2019$ Indian Society of Neuroanaesthesiology and Critical Care
License terms

()(1) $\Theta \circledast$ 
anticoagulant use, and amyloid angiopathy in aging populations. $^{2-7}$ Despite lengthy stays in critical care units, only one-half of those experiencing an ICH survive after 30 days, and those who do are often left with considerable disability. ${ }^{6}$

Treatment of ICH has traditionally focused on minimizing hemorrhage expansion and reducing clot volume through both medical and surgical means. ${ }^{8}$ Despite being the second-most common stroke subtype, it remains the last form of stroke without a specific therapy. ${ }^{3}$ This article aims to introduce the most common types of ICH, describe the pathophysiology of secondary neurological injury after bleeding, and briefly discuss the emergency and intensive care management of the ICH patient, with special emphasis on evidence-based medical management and surgical techniques for the primary treatment of the ICH. While the topic of ICH is vast, this review aims to acquaint the emergency physicians and neurointensivists/neuroanesthesiologists to the latest evidence and guidelines for the management of ICH. This article is by no means comprehensive in its coverage, with the authors' aim for it to be a succinct review only.

\section{Etiology of Intracerebral Hemorrhage}

Primary ICH is defined as an ICH in the absence of a clear underlying lesion. ICH occurs after rupture of an intraparenchymal vessel in the brain, the mechanisms for which can be disparate. The etiology of ICH must be determined by exclusion of secondary causes by a thorough investigation. We briefly examine three common etiologies encountered in clinical practice.

Hypertensive vasculopathy: Hypertensive bleeding comprises over $80 \%$ of ICH etiologies. ${ }^{9}$ HTN is the strongest risk factor for ICH. Using pooled data from 22 separate countries including India, HTN has been reported to account for $74 \%$ of the population susceptible to risk, and considered as the primary cause. ${ }^{10}$ Chronic HTN causes lipohyalinosis of small intraparenchymal arterioles and leads to the development of Charcot-Bouchard microaneurysms. Development of these aneurysms is thought to promote hypertensive $\mathrm{ICH}$. These hemorrhages classically involve the rupture of small lipohyalinized vessels within the basal ganglia, thalamus, cerebellum, and pons. ${ }^{11,12}$ Though the anatomical location of CharcotBouchard aneurysms supports their role in the development of ICH, their causal relationship remains uncertain.

Cerebral amyloid angiopathy: Cerebral amyloid angiopathy (CAA) is the result of $\beta$-amyloid deposition in the walls of the cerebral vessels, especially the medium and small arteries in the cortex and leptomeninges. ${ }^{13}$ Because the preferentially affected vessels tend to be superficial, ICH due to CAA is predominantly lobar. CAA should be suspected in elderly patients with recurrent or simultaneous lobar ICH. ${ }^{14}$ It is also frequently associated with Alzheimer's dementia, in whom $83 \%$ will have evidence of CAA on autopsy, the severity of CAA correlating with the likelihood of ICH. ${ }^{15}$

Antithrombotic-related ICH: Bleeding disorders due to primary abnormalities of anticoagulation are rare causes of ICH, but antithrombotic-related cases account for up to $14 \%$ of ICH. ${ }^{16}$ Treatment with oral anticoagulants increases the risk of ICH by 7- to 11-fold compared to otherwise similar individuals not receiving anticoagulation. ${ }^{16}$ Similarly, treatment of acute ischemic stroke with recombinant tissue plasminogen activator (rt-PA) increases the risk by 10 -fold in comparison to placebo. ${ }^{17}$ Because people on anticoagulation are also more likely to be elderly, angiopathies such as CAA may also play a causal role. ${ }^{18}$ ( - Table $\mathbf{1}$ )

\section{Pathophysiology of Secondary Neurological Injury}

Independent of the primary cause of $\mathrm{ICH}$, secondary injury from the presence of parenchymal blood mediates further neurological injury. Perihematomal edema and disordered cerebral autoregulation resulting in delayed ischemia are two areas of ICH pathophysiology that lend themselves to further study, importantly as possible targets to prevent secondary injury. ${ }^{\text {? }}$

Perihematomal edema: Perihematomal edema (PHE) is the formation of edema around the original hematoma, and serves as a radiological manifestation of secondary injury. The edema itself forms as a multipart process evolving from the time of initial hemorrhage. Early PHE starts as hematoma retraction and hematomal hydrostatic pressure changes, forcing serum into the perihematomal space. Late PHE develops from thrombin formation, hemolysis of red blood cells, and hemoglobin toxicity. This leads to complement activation, plasma protein leakage, and blood-brain barrier disruption. ${ }^{19,20}$ PHE is clinically significant, contributing not only to increased mass effect, but also to progressive tissue injury and poorer neurological outcomes after $\mathrm{ICH}^{21}$ Earlier studies on PHE and outcomes were limited due to differences in outcome measures, imaging time points, and PHE assessment parameters. ${ }^{22}$ From more recent studies, both baseline PHE and rate of PHE expansion have significant impact on neurological morbidity. A pooled analysis of the INTERACT 1 and 2 trials assessed PHE as the interval increase in absolute

Table 1 Causes of intracerebral hemorrhage

\begin{tabular}{|l|}
\hline Causes of intracerebral hemorrhage \\
\hline Hypertensive vasculopathy \\
\hline Aneurysmal rupture \\
\hline Coagulopathy \\
\hline Cerebral amyloid angiopathy \\
\hline Intracranial neoplasm \\
\hline Hemorrhagic transformation of infarct \\
\hline Cerebral venous sinus thrombosis \\
\hline Moyamoya disease \\
\hline Vascular malformation \\
\hline Traumatic brain injury \\
\hline Vasculitis \\
\hline Infection \\
\hline Sympathomimetic drug abuse \\
\hline Reversible cerebral vasoconstriction syndrome \\
\hline Septic embolism mycotic aneurysm \\
\hline
\end{tabular}


volume during 24 hours and reported a significant association with poor outcomes. ${ }^{23}$ Similarly, a retrospective single-center study of 139 patients found that PHE expansion rate between admission and 24 hours was a significant predictor of poor functional outcome and 90-day mortality. ${ }^{24,25}$ More recently, the time interval for PHE assessment has been extended. The larger VISTA study of 596 patients with ICH assessed the effect of PHE volume expansion in the first 72 hours on functional outcome, with a subgroup analysis based on ICH location. The 72-hour PHE expansion was associated with significantly greater odds of poor neurological outcome, particularly in basal ganglia hematomas. ${ }^{21}$ The 2017 Helsinki ICH study also confirmed that patients with faster PHE growth at 72 hours had increased midline shift as well as higher rates of herniation and 6-month mortality. ${ }^{26}$

Magnetic resonance imaging (MRI) is the preferred modality for assessing PHE, as delineation of PHE border zones on computed tomography (CT) can be particularly difficult in patients with periventricular leukoaraiosis. The time course of PHE is variable-edema may form as early as a few hours, evolve over 1 to 2 weeks, and persist as long as a month. ${ }^{27} \mathrm{~A}$ small prospective study measuring PHE by MRI found PHE to have its fastest growth within the first 48 hours after hemorrhage, and reaching its maximum volume in an average of 12 days after the onset. Factors in delayed PHE include hyperglycemia, coagulation factors, and hematoma volume. ${ }^{22}$ Hematoma volume is thought to be a particular risk factor for delayed PHE as brain parenchyma is exposed to a higher burden of erythrocyte degradation products over time. ${ }^{28}$

Due to its impact on secondary injury, PHE is a target for therapeutic intervention in ICH. Studies on PHE evolution suggest interventions targeting PHE should be initiated early and maintained over the first 3 to 7 days as possible. ${ }^{26,28}$

Disordered cerebral autoregulation and secondary ischemia in ICH: Disordered cerebral autoregulation (CA) and secondary ischemia in ICH too is an important cause for further secondary injury. ${ }^{29}$ Remote ischemic lesions are found in approximately $25 \%$ of patients 30 days after $\mathrm{ICH}^{30}$ The lesions are typically multiple, small, and subcortical. These likely arise from a combination of hematoma volume causing both local and global raised intracranial pressure (ICP), cerebral cytotoxic injury leading to inflammation and a thrombotic milieu, and poor CA. ICH is often associated with a rise in ICP due to hematoma mass effect; this increase in global or compartmental ICP may reduce cerebral perfusion pressure (CPP). CA is a protective feedback mechanism to provide relatively constant blood flow to the brain as a response to changing CPP. This regulatory mechanism can be impaired in $\mathrm{ICH}$. As blood pressure (BP) control is currently one of the pillars of post-ICH stabilization and care, an understanding of the patient's CA is crucial to ensure adequate cerebral blood flow. Aggressive lowering of BP may lead to hypoperfusion and ischemia, while higher BPs may lead to hyperemia and delayed hematoma expansion. An increasing number of studies are now correlating impaired CA with worsened clinical outcomes. ${ }^{31-33}$ Autoregulation-oriented therapy is an emerging concept that uses transcranial Doppler ultrasound at the bedside to assess an individual patient's autoregulatory status and adjust BP and CPP goals accordingly. Outcomes based on this approach are yet to be determined. ${ }^{31,32}$

\section{Clinical Management of Intracerebral Hemorrhage}

Management of ICH is a complex and multidisciplinary process that begins with patient contact either on the field or in the emergency room. For completeness of the review, we will touch upon most medical and surgical aspects of management as a key for the practicing intensivist to refer to original trials and research in the field.

As a true neurological emergency, ICH patients are best managed in a dedicated neurocritical care or stroke unit for at least the first 24 to 48 hours as this has been shown to reduce the likelihood of mortality, ${ }^{34}$ and a Swedish cohort showed that these units were associated with better longterm survival. ${ }^{35}$ This acute period is usually associated with rapid deterioration because of hematoma expansion, intraventricular extension, and uncontrolled HTN.

\section{Imaging in Acute Intracerebral Hemorrhage}

The first step in the workup of an acute onset focal neurological deficit suggestive of a stroke is to obtain a non-contrast-enhanced head CT to differentiate between ischemic and hemorrhagic strokes. ${ }^{36}$ The American Heart Association guidelines recommend an initial CT scan as the gold standard or an MRI of the brain as mandatory in the workup of ICH. ${ }^{37}$ Serial head imaging by CT or MRI can evaluate for interval expansion or evolving mass effect, both of which may prompt changes in patient's management. The bulk of hematoma expansion takes place during the first 3 hours after symptom onset and hence earlier imaging usually predicts hematoma expansion, ${ }^{38}$ which is usually associated with a neurological decline, with stability of hematoma occurring at about 24 hours. ${ }^{39}$ Initial size of hematoma, intraventricular extension of the hemorrhage, and expansion of hematoma are all associated with a worse prognosis. The ICH score includes five components-the Glasgow Coma Scale (GCS) score, age, volume of ICH, presence of intraventricular hemorrhage (IVH), and infratentorial origin of bleed. These variables are all well-validated strong risk factors for 30-day mortality, and the ICH score has come to be widely used in current clinical practice. ${ }^{40}$ Perhaps equally valuable, but less widespread, is the FUNC score that prognosticates the likelihood of functional independence at 90 days based on similar characteristics at presentation. ${ }^{41}$ Recommendations for timing of imaging varies from patient to patient, but should at least occur within 3 hours of onset, at the time of a neurological decline, and at 24-hour follow-up..$^{42}$ ( - Fig. 1)

When the clinical presentation is suspicious for a nonhypertensive etiology, such as in patients under 50 years of age, CT angiography can be used to predict a patient's risk of harboring an underlying vascular etiology with the aid of the Secondary Intracerebral Hemorrhage (SICH) score. The SICH score is calculated by assigning points based on a patient's imaging findings, age group, sex, and presence of HTN or 


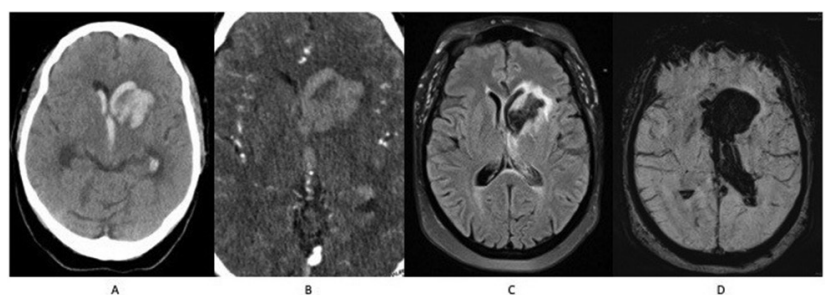

Fig. 1 Typical hypertensive ICH on CT, CTA, and MRI. (A) Noncontrast head $\mathrm{CT}$ showing hypertensive ICH with IVH originating in the left putaminal region. (B) CTA to rule out any vascular malformation as the cause of bleeding. Also absent is the "spot sign," as no contrast extravasation is seen in the substance of the ICH. (C) MRI FLAIR and (D) MRI SWI sequence showing "blooming artifact" of the same ICH. Abbreviations: CT, computed tomography; CTA, CT angiography; FLAIR, fluid-attenuated inversion recovery; ICH, intracerebral hemorrhage; IVH, intraventricular hemorrhage; MRI, magnetic resonance imaging; SWI, susceptibility-weighted image.

impaired coagulation, with a range of 0 to 6 . The highest incidences of vascular lesions are observed in patients with $\mathrm{SICH}$ scores of $3(18.5 \%)$ and up to $6(100 \%){ }^{43}$

Spot sign: Active bleeding into the hematoma causes contrast extravasation within the hematoma. This produces a hyperdense spot called the spot sign, which can be seen on both CT angiography and contrast-enhanced CT. Presence of the spot sign indicates a high likelihood of early hematoma expansion, occurring in over $75 \%$ of these patients. ${ }^{44}$ Characteristics of the spot sign can be used as further independent predictors, including presence of multiple spot signs, maximal diameter, and maximal attenuation. ${ }^{45,46}$

Blend Sign I \& II: When CT performed within 24 hours of onset shows that the hematoma is made of two differing densities, and the boundary between them is blurred, this is called the Blend Sign II. The difference in CT value of the two densities must be at least 10 Hounsfield units. This finding is associated with a mortality rate that is 7 times higher, and a rebleeding rate that is 10 times higher, than those without the sign. ${ }^{47}$ When the boundary between the two hematomas can be clearly distinguished, it is called the Blend Sign I; the rebleed rates, prognosis, and mortality rates were not statistically different than those of controls. ${ }^{47}$

Fluid level on head CT: A CT fluid-blood level is a region within an ICH with an upper compartment that is hypodense to the brain, a lower compartment that is hyperdense to the brain, and a sharply defined horizontal interface between these compartments. This is a relatively rare finding that is only $59 \%$ sensitive but $98 \%$ specific for the presence of coagulopathy, and should prompt a thorough investigation. ${ }^{48}$ (-Fig. 2)

\section{Principles of Medical Management Intracerebral Hemorrhage}

Management of ICH begins at the first contact with emergency services and continues to the emergency department and thence to the intensive care unit. The "Golden Hour" after ictus dictates a parallel, multipronged approach to stabilization and treatment of the patient.

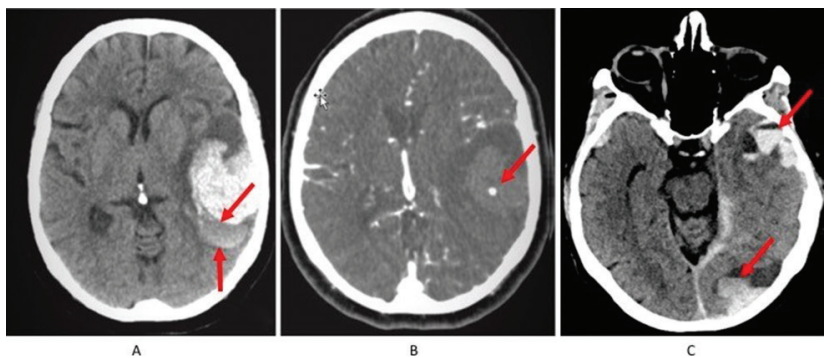

Fig. 2 Blend sign, spot sign, and fluid-blood level on CT and CTA. (A) Noncontrast CT scan of blend sign I, showing two differing densities of ICH. (B) Contrasted CTA showing spot sign with hyperdense spot of contrast extravasation. (C) Fluid-blood level seen in multifocal ICH related to anticoagulant use. Red arrows indicate respective signs. CTA, CT angiography; ICH, intracerebral hemorrhage. Panels A and B were reproduced with permission from Jong S. Kim, Editor-in-Chief, Journal of Stroke from article: Sporns PB, Schwake M, Kemmling A, et al. Comparison of spot sign, blend sign and black hole sign for outcome prediction in patients with intracerebral hemorrhage. J Stroke. 2017; 19 (3):333-339.

Specific ICH-related medical management involves: (1) treatment of HTN, (2) treatment of coagulopathy, (3) minimizing rise in ICP, (4) prevention of complications, and (5) post-ICH long-term therapeutic decisions (-Table 2 ).

Blood Pressure Control: Uncontrolled, high BP is associated with hematoma expansion, neurological deterioration, and poor outcomes in the form of increased mortality and dependency. ${ }^{49,50}$ The INTERACT- 2 study was the first major and largest international randomized controlled trial (RCT) to examine HTN and ICH occurring in the prior 6 hours, by assigning patients to an intensive BP reduction to $<140 \mathrm{~mm} \mathrm{Hg}$ or routine BP treatment to $<180 \mathrm{~mm}$ Hg. ${ }^{51}$ Intensive treatment of BP failed to result in reduction of hematoma volume or improvement in outcomes, rates of death, and disability. Criticisms of the trial included the approximate 10-hour delay from ictus to treatment, a critical time period when most hematomas increase in size. The more recent ATACH 2 trial enrolled patients with ICH volume $<60 \mathrm{~mL}$ within 4.5 hours of onset and randomized them to either intensive BP lowering $(110-139 \mathrm{~mm} \mathrm{Hg}$ ) or standard BP lowering (140-179 mm Hg), with the trial failing to show a difference in death or disability at 3 months. ${ }^{52}$ The trial did show a nonsignificant trend toward decreased hematoma volume expansion in the intensive treatment group. It is also useful to note that the duration of intensive treatment in ATACH 2 was only 24 hours, while the INTERACT 2 study treated BPs for 7 days. ATACH 2 also seemed to have higher incidence of adverse renal events with intensive BP treatment. Our take-away message from these trials mirrors the guidelines ${ }^{1,37,53}$ and it may be reasonable to target a BP between $140 \mathrm{~mm} \mathrm{Hg}$ and $180 \mathrm{~mm} \mathrm{Hg}$ early after ICH and use patient-specific criteria such as the presence of chronic HTN to further determine the exact level.

Hemostasis: Achieving hemostasis in patients on antiplatelet and anticoagulant medications is a growing challenge in the field. Using procoagulants to stop hematoma growth has been tried with varying degrees of success. The FAST trial using recombinant activated factor VIla failed to 
Table 2 The "Golden Hour": early medical stabilization after ICH

Admission to the emergency department with subsequent triage to intensive care unit with close neurological monitoring capability

ABCs: Intubate and secure airway if necessary, preferably with rapid-sequence intubation, paying close attention to blood pressure and hemodynamics, so as to not drop the CPP in the setting of raised ICP. Maintain adequate perfusion with close hemodynamic monitoring

Rapid imaging with CT/CTA, or MRI-if any significant delays can be avoided

Concise clinical assessment, neurological examination, and grading scales including GCS, NIHSS, ICH, and FUNC scores

If raised ICP suspected:

- Raise head of bed to 30 degrees

- Hyperventilate as a temporary, empiric measure to reduce ICP, if high ICP suspected. Regulate and discontinue once more if definitive information is available. Employ $\mathrm{CO}_{2}$ monitoring, maintain $\mathrm{PaCO}_{2}$ and/or $\mathrm{EtCO}_{2}$ at $30-35 \mathrm{~mm} \mathrm{Hg}$ to control extent of hyperventilation

- Adequate sedation and analgesia. If intubated, use propofol or midazolam infusion, \pm opioids such as morphine or fentanyl, with initial RASS goal of 0 to-1

- Empiric hyperosmolar therapy if imminent herniation suspected. Used only as a temporizing measure while definitive surgical interventions are being planned. Can use mannitol $1 \mathrm{~g} / \mathrm{kg}$ dose, infused peripherally or hypertonic saline at available concentration, like $30 \mathrm{~mL}$ of $23.4 \% \mathrm{NaCl}$ solution, infused centrally

Initiate potential early interventions: (see details in the text section)

- Control of elevated blood pressure

- Correction of coagulopathy

- Early surgical intervention

Strict normothermia: $36-37.5^{\circ} \mathrm{C}$, with antipyretics, surface, or internal cooling

Maintain blood sugars 120-180 mg/dL

Recognize and treat seizures emergently, obtain EEG if low GCS and poor mentation to rule out nonconvulsive seizures and/or status epilepticus

Abbreviations: $\mathrm{ABC}$, airway, breathing, circulation; $\mathrm{CO}_{2}$, carbon dioxide; $\mathrm{CPP}$, cerebral perfusion pressure; $\mathrm{CT}$, computerized tomography, $\mathrm{CTA}$, $\mathrm{CT}$ angiography; EEG, electroencephalogram; GCS, Glasgow Coma Scale; $\mathrm{EtCO}_{2}$, end-tidal $\mathrm{CO}_{2}$; ICH, intracerebral hemorrhage; ICP, intracranial pressure; MRI, magnetic resonance imaging; $\mathrm{NaCl}$, sodium chloride; NIHSS, National Institutes of Health Stroke $\mathrm{Scale}$; PaCO, partial pressure of $\mathrm{CO}_{2}$; RASS, Richmond Agitation-Sedation Scale.

Note: Adapted and modified from Hemphill and Lam. ${ }^{1}$

show any clinical benefit and has largely been abandoned. ${ }^{54}$ Tranexamic acid (TXA) is another agent that promotes hemostasis by blocking plasmin binding to fibrin and preventing the breakdown of the clot. The CRASH-2 trial in trauma patients showed a reduction in mortality ${ }^{55}$ with TXA, while the CRASH-3 trial (NCT01402882) with a focus on traumatic brain injury is still ongoing. The recently concluded TICH-2 trial administered TXA in the acute period as a bolus and infusion compared to placebo. There was no difference in the functional status between the groups despite reduction in early deaths and serious adverse events. ${ }^{56}$ Multiple other trials including TRAIGE (NCT02625948) and TRANSACT (NCT03044184) are currently evaluating TXA in spontaneous $\mathrm{ICH}$. Unless there is an unplanned delay in definitive surgical management, TXA is not widely used in ICH management, but remains an option in such situations.

Coagulopathy reversal: Anticoagulant-related $\mathrm{ICH}$ is becoming an ever more frequent problem, especially in the developed world, with ICH being the cause of $58 \%$ of bleeding-associated deaths in anticoagulated people, ${ }^{57}$ and with a higher mortality than ICH in patients without antiplatelet or anticoagulant use. ${ }^{58}$ Hematoma growth also occurs frequently and possibly over a more prolonged period in anticoagulated patients. We will specifically consider therapeutic measures in the setting of ICH with vitamin $\mathrm{K}$ antagonists (VKAs) and direct oral anticoagulants (DOACs).

VKAs such as warfarin inhibits the synthesis of vitamin K-dependent coagulation factors II, VII, IX, and X, and proteins $\mathrm{C}$ and $\mathrm{S}$ in the liver. Stopping the agent is the first step, while replenishing deficient factors is of paramount importance. Intravenous vitamin $\mathrm{K}$ is usually administered in the acute presentation, but usually takes 2 to 4 days for effects due to a lag in hepatic synthesis and is not useful for immediate reversal. Fresh frozen plasma (FFP) is still used in various parts of the globe for immediate reversal, but is increasingly less in favor because of the risk of infection (human immunodeficiency virus, hepatitis $\mathrm{B} / \mathrm{C}$ ), allergic/transfusion reactions, volume overload, delay in administration because of need to thaw, need for blood typing, cross-matching, and inadequate correction of international normalized ratio. Prothrombin complex concentrates (PCCs), a heterogeneous assortment of plasma-derived vitamin K-dependent clotting factors, are more frequently used because they are readily available without the need for compatibility testing, can be infused over a very short duration in a low volume, and have an almost immediate onset of action. The INCH trial showed that PCCs reduced early hematoma growth and early mortality attributable to hematoma growth when compared to FFP. ${ }^{59}$ 
Currently, nonactivated 4-factor PCCs (KCentra) and activated PCCs (FEIBA) are preferred over 3-factor PCCs in routine reversal of anticoagulation.

DOACs include direct thrombin inhibitors, such as dabigatran, and factor Xa inhibitors (FXa-Is), such as apixaban, rivaroxaban, and edoxaban, and are becoming extremely popular because of their reliable effects and lack of need for hematological monitoring. Idarucizumab, a monoclonal antibody specific to dabigatran, has recently become available and was shown to be rapid, durable, and safe in reversal of anticoagulant activity of dabigatran, ${ }^{60}$ while hemodialysis can also be used. Andexanet alfa is a new, modified, recombinant, inactive form of FXa with no procoagulant effects, designed to specifically bind and sequester FXa-inhibitor molecules and has been approved for FXa-I reversal. ${ }^{61}$ The dose needs adjustment based on the agent used and the time since the last dose. With the results of the ANNEXA-4 trial, ${ }^{61}$ andexanet has been approved, but costs in the United States still remain prohibitively high. Another reversal agent ciraparantag supposedly binds all DOACs and has thus far been tested in healthy subjects. ${ }^{62}$ ( - Tables 3 and $\mathbf{4}$ )

There has been a lack of clarity about effect of antiplatelets on hematoma expansion and outcomes. ${ }^{63-66}$ The PATCH trial found that patients with ICH who received platelet transfusions were actually likely to have poorer outcomes than those who did not. ${ }^{67}$ As the guidelines suggest, one needs to be aware of the numerous risks of platelet transfusion and probably reserve transfusion for patients undergoing urgent neurosurgical intervention, ${ }^{68}$ while more trials are needed to decide the safest option. Consideration for the half-life of the antiplatelet agent used and presence of active metabolites of the drugs may help decide the timing of administration of platelets, while single-donor platelets might be superior to pooled units. ${ }^{68,69}$ Desmopressin (DDAVP) has been shown to reduce bleeding time and normalize hemostasis in patients with uremic platelets undergoing surgery, ${ }^{70}$ while uremic platelets exposed to aspirin have been shown to have improved function after DDAVP administration. ${ }^{71}$ One study examined patients with ICH and reduced platelet activity on point-of-care testing and/or known aspirin use, administered DDAVP to them, and showed improved platelet function, increase in von Willebrand factor antigen, and reduced rate of hematoma growth. ${ }^{72}$ This and other small case series allude to the value of DDAVP administration.

Venous thromboembolism (VTE) prophylaxis: ICH patients are at the risk for VTE, including deep vein thrombosis (DVT) and pulmonary embolism. The CLOTS 3 trial showed the benefit of intermittent pneumatic compression (IPC) in reducing the rate of proximal DVT. ${ }^{73}$ The guidelines recommend the use of IPC devices in addition to elastic stockings for prevention of VTE, ${ }^{74}$ while after documentation of cessation of bleeding, low-dose, low-molecular weight or unfractionated heparin may be considered for prevention in patients at high risk for VTE after 1 to 4 days from ICH onset. ${ }^{74}$ There is a lack of consensus about the treatment of VTE in the setting of acute ICH and a risk-benefit approach might be most prudent.

\section{Surgical Management of Intracerebral Hemorrhage}

This usually proceeds in parallel with medical management. Unless the bleed is severe and there is rapid worsening, surgical options are best considered after initial medical stabilization. Though no surgical option has been shown to improve mortality and outcomes definitively, numerous trials have been conducted in an attempt to (1) reduce hematoma volume, (2) decrease ICP, (3) limit expansion of hematoma, and (4) counter secondary brain injury (by the toxic effect of blood products on the parenchyma) by evacuation. ${ }^{1}$ As outlined in the section on the pathophysiology, removal of the hematoma in theory should mitigate the above effects.

ICP monitoring: This is usually the first surgical step in the management of ICH, a largely empiric approach adopted in patients with a GCS score of 8 or less and/or a rapidly deteriorating neurological exam. ${ }^{75}$ The goal is to maintain CPP (50-70 $\mathrm{mm} \mathrm{Hg}$ ) and effective cerebrospinal fluid (CSF) diversion to maintain ICP. ${ }^{76}$ Practical considerations against ICP monitoring are risk of infection and bleeding, while the true value of ICP monitoring might be appreciated in the setting of herniation, significant IVH, or hydrocephalus. ${ }^{37}$

Surgical evacuation: The strongest evidence for definitive and emergent surgical management is for infratentorial hematomas as outlined by the 2015 American Heart Association Guidelines with Class I Recommendation; level of evidence B. ${ }^{37}$ Cerebellar hematomas $>3 \mathrm{~cm}$ in diameter, evidence of brainstem compression/herniation, and hydrocephalus all warrant immediate surgical evacuation over just ventricular drainage. ${ }^{77,78}$

Surgical approaches to ICH can be broadly classified into (1) open craniotomy and (2) minimally invasive procedures.

Open craniotomy: This is relatively easier to perform and, on a global scale, demands less resources and infrastructure. The skill of the surgeon and the patient's condition are the primary determinants. A meta-analysis of 15 RCTs that compared standard surgical evacuation to conservative medical care alone pooled 2,059 subjects and found an odds ratio of $0.74(p<0.0001)$ in favor of standard craniotomy for $\mathrm{ICH}^{79}$ with the caveat that while craniotomy was usually offered to patients with rapid decline, none of the trials specifically considered this population. Both the landmark STICH I and STICH II trials explored the effectiveness of early surgical evacuation versus best medical management, with STICH II being conducted on more superficial lobar hemorrhages without ventricular extension, after subgroup analysis of STICH I had revealed a possible benefit of surgery in these patients. ${ }^{80,81}$ Neither study was able to show any benefit or improved outcomes from hematoma evacuation. It is useful to note that a good proportion of patients in the medical arm of STICH I had delayed surgery and still did not show benefit. Another metaanalysis of eight prospective RCTs of surgical treatment for spontaneous ICH showed improved outcomes if surgery was performed within 8 hours, hematoma volume was between 20 and $50 \mathrm{~mL}$, GCS score of 9 to 12 , or patient age was 50 to 69 years. ${ }^{82}$ While many surgical groups have reported their experiences, no trials have evaluated the effectiveness of 
Table 3 Summary of recommendations for reversal of antithrombotic agents in patients with intracranial hemorrhage

\begin{tabular}{|c|c|c|}
\hline Antithrombotic Agent & Reversal Agent & Comments \\
\hline Vitamin K antagonists Warfarin & $\begin{array}{l}\text { If INR } \geq 1.4: \\
\text { Vitamin K } 10 \mathrm{mg} \text { IV, plus } 3 \text { or } 4 \text { factor PCC IV } \\
\text { (dosing based on weight, INR and PCC type) } \\
\text { OR } \\
\text { FFP } 10-15 \mathrm{ml} / \mathrm{kg} \text { IV if PCC not available }\end{array}$ & $\begin{array}{l}\text { Discontinue VKa in setting of ICH. } \\
\text { Avoid reversal in cerebral venous sinus } \\
\text { thrombosis-associated ICH. Assess } \\
\text { risk-benefit in the setting of concur- } \\
\text { rent symptomatic or life-threatening } \\
\text { thrombosis, ischemia, heparin-induced } \\
\text { thrombocytopenia, or disseminated in- } \\
\text { travascular coagulation. If INR resistant } \\
\text { to PCC and > 1.4, consider FFP. Avoid } \\
\text { rFVIla }\end{array}$ \\
\hline $\begin{array}{l}\text { Direct factor Xa inhibitors } \\
\text { Rivaroxaban } \\
\text { Apixaban } \\
\text { Edoxaban }\end{array}$ & $\begin{array}{l}\text { For Rivaroxaban and Apixaban: } \\
\text { Andexanet Alfa aDosing details see Table } 4 \\
\text { Activated charcoal ( } 50 \mathrm{~g} \text { ) within } 2 \text { h of } \\
\text { ingestion, } \\
\text { Activated PCC (FEIBA) } 50 \text { units/kg IV } \\
\text { OR } \\
4 \text { factor PCC } 50 \text { units/kg IV }\end{array}$ & $\begin{array}{l}\text { Discontinue factor Xa inhibitors in the } \\
\text { setting of ICH. Reversal to be guided by } \\
\text { clinical indication of bleeding and not } \\
\text { laboratory testing }\end{array}$ \\
\hline $\begin{array}{l}\text { Direct thrombin inhibitors } \\
\text { Dabigatran } \\
\text { Argatroban } \\
\text { Bivalirudin } \\
\text { Desirudin } \\
\text { Lepirudin }\end{array}$ & $\begin{array}{l}\text { For dabigatran reversal: } \\
\text { Activated charcoal ( } 50 \mathrm{~g} \text { ) within } 2 \text { h of } \\
\text { ingestion, } \\
\text { AND } \\
\text { Idarucizumab } 5 \mathrm{~g} \mathrm{IV} \mathrm{(in} \mathrm{two} 2.5 \mathrm{~g} / 50 \mathrm{~mL} \\
\text { vials) } \\
\text { Consider hemodialysis or idarucizumab } \\
\text { redosing for refractory bleeding after initial } \\
\text { administration. } \\
\text { For other DTIs: } \\
\text { Activated PCC (FEIBA) } 50 \text { units } / \mathrm{kg} \text { IV } \\
\text { OR } \\
4 \text { factor PCC } 50 \text { units } / \mathrm{kg} \mathrm{IV}\end{array}$ & $\begin{array}{l}\text { Discontinue DTIs in the setting of ICH. } \\
\text { Reversal to be guided by clinical indi- } \\
\text { cation of bleeding and not laboratory } \\
\text { testing. Avoid FFP or rFVIla for DTI-asso- } \\
\text { ciated ICH }\end{array}$ \\
\hline Unfractionated heparin & $\begin{array}{l}\text { Protamine } 1 \mathrm{mg} \text { IV for every } 100 \text { units of } \\
\text { heparin administered in the previous } 2-3 \mathrm{~h} \\
\text { (up to } 50 \mathrm{mg} \text { in a single dose) }\end{array}$ & $\begin{array}{l}\text { Discontinue heparin infusion in setting } \\
\text { of ICH. Reverse if on full dose antico- } \\
\text { agulation and avoid if on prophylactic } \\
\text { subcutaneous dosing. Use protamine as } \\
\text { indicated }\end{array}$ \\
\hline $\begin{array}{l}\text { Low-molecular weight heparins } \\
\text { Enoxaparin } \\
\text { Dalteparin } \\
\text { Nadroparin } \\
\text { Tinzaparin } \\
\text { Danaparoid }\end{array}$ & $\begin{array}{l}\text { Enoxaparin: } \\
\text { Dosed within } 8 \text { h: Protamine } 1 \mathrm{mg} \text { IV per } 1 \\
\text { mg enoxaparin (up to } 50 \mathrm{mg} \text { in a single dose) } \\
\text { Dosed within } 8-12 \mathrm{~h} \text { : Protamine } 0.5 \mathrm{mg} \text { IV } \\
\text { per } 1 \mathrm{mg} \text { enoxaparin (up to } 50 \mathrm{mg} \text { in a single } \\
\text { dose) } \\
\text { Minimal utility in reversal > } 12 \mathrm{~h} \text { from dosing } \\
\text { Dalteparin, Nadroparin and Tinzaparin: } \\
\text { Dosed within } 3-5 \text { half-lives of LMWH: Prota- } \\
\text { mine } 1 \mathrm{mg} \text { IV per } 100 \text { anti-Xa units of LMWH } \\
\text { (up to } 50 \mathrm{mg} \text { in a single dose) } \\
\text { OR } \\
\text { rFVIla } 90 \mathrm{mcg} / \mathrm{kg} \text { IV if protamine is } \\
\text { contraindicated }\end{array}$ & $\begin{array}{l}\text { Discontinue LMWH in setting of ICH and } \\
\text { reverse if being given therapeutic doses } \\
\text { of anticoagulation. Administer prota- } \\
\text { mine as shown. If protamine contrain- } \\
\text { dicated, consider rFVIla. Do not reverse } \\
\text { for prophylactic doses of LMWH. Avoid } \\
\text { using FFP, PCC, or aPCC for reversal }\end{array}$ \\
\hline Danaparoid & rFVIla 90 mcg/kg IV & \\
\hline $\begin{array}{l}\text { Pentasaccharides } \\
\text { Fondaparinux }\end{array}$ & $\begin{array}{l}\text { Activated PCC (FEIBA) } 20 \text { units/kg IV or rFVIla } \\
90 \mathrm{mcg} / \mathrm{kg} \text { IV }\end{array}$ & $\begin{array}{l}\text { Discontinue agent, administer aPCC or } \\
\text { rFVIla, do not use protamine. If being } \\
\text { used for venous thromboembolism in } \\
\text { the setting of ICH, no need for reversal } \\
\text { unless evidence of bioaccumulation or } \\
\text { impaired clearance }\end{array}$ \\
\hline
\end{tabular}


continued

\begin{tabular}{|c|c|c|}
\hline Antithrombotic Agent & Reversal Agent & Comments \\
\hline $\begin{array}{l}\text { Thrombolytic agents (plasmino- } \\
\text { gen activators) } \\
\text { Alteplase } \\
\text { Reteplase } \\
\text { Tenecteplase }\end{array}$ & $\begin{array}{l}\text { Cryoprecipitate } 10 \text { units IV } \\
\text { OR } \\
\text { Antifibrinolytics (tranexamic acid } 10-15 \mathrm{mg} / \mathrm{kg} \\
\text { IV over } 20 \text { min or e-aminocaproic acid } 4-5 \mathrm{~g} \\
\text { IV) if cryoprecipitate is contraindicated }\end{array}$ & $\begin{array}{l}\text { Discontinue thrombolytic agent in set- } \\
\text { ting of ICH, cryoprecipitate in first } 24 \\
\text { hours after thrombolytic agent use, or } \\
\text { antifibrinolytic agent if contraindication } \\
\text { to cryoprecipitate, check fibrinogen } \\
\text { levels and repeat agent if necessary }\end{array}$ \\
\hline Antiplatelet agents & $\begin{array}{l}\text { DDAVP } 0.4 \mu \mathrm{g} / \mathrm{kg} \text { IV times } 1 \\
\text { If neurosurgical intervention: Platelet transfu- } \\
\text { sion (one apheresis unit) }\end{array}$ & $\begin{array}{l}\text { Discontinue antiplatelet agents in set- } \\
\text { ting of ICH, avoid platelet transfusion in } \\
\text { patients with no planned neurosurgical } \\
\text { intervention, obtain platelet function } \\
\text { testing if possible, consider DDAVP for } \\
\text { use in conjunction with platelets }\end{array}$ \\
\hline
\end{tabular}

Abbreviations: DDAVP: desmopressin; DTI, direct thrombin inhibitor; FEIBA, factor eight inhibitor bypassing activity; FFP, fresh frozen plasma; INR, international normalized ratio; IV, intravenous; LWMH: low-molecular weight heparin; rFVIla, recombinant factor VIla; PCC, prothrombin complex concentrates.

Note: Reproduced from Frontera et al. ${ }^{68}$

aFor dosing details see Table 4.

Table 4 Andexanet alfa dosing

\begin{tabular}{|c|c|c|c|}
\hline \multirow[t]{2}{*}{ FXa Inhibitor } & \multirow[t]{2}{*}{ FXa Inhibitor last dose } & \multicolumn{2}{|c|}{ Timing of FXa inhibitor last dose before andexanet alfa initiation } \\
\hline & & $<8$ h or unknown & $\geq 8 \mathrm{~h}$ \\
\hline \multirow[t]{2}{*}{ Rivaroxaban } & $\leq 10 \mathrm{mg}$ & Low dose & \multirow{4}{*}{ Low dose } \\
\hline & $>10 \mathrm{mg}$ or unknown & High dose & \\
\hline \multirow[t]{2}{*}{ Apixaban } & $\leq 5 \mathrm{mg}$ & Low dose & \\
\hline & $>5 \mathrm{mg}$ or unknown & High dose & \\
\hline Dose & \multicolumn{2}{|l|}{ Initial IV bolus } & Follow-on IV infusion \\
\hline Low dose & \multicolumn{2}{|c|}{$400 \mathrm{mg}$ at target rate of $30 \mathrm{mg} / \mathrm{min}$} & $4 \mathrm{mg} / \mathrm{min}$ for up to $120 \mathrm{~min}$ \\
\hline High dose & \multicolumn{2}{|c|}{$800 \mathrm{mg}$ at target rate of $30 \mathrm{mg} / \mathrm{min}$} & $8 \mathrm{mg} / \mathrm{min}$ for up to $120 \mathrm{~min}$ \\
\hline
\end{tabular}

Abbreviations: FXa, factor Xa; IV, intravenous.

Note: Andexxa (andexanet alfa) prescribing information: Portola Pharmaceuticals, Inc; May 2019.

decompressive hemicraniectomy with or without hematoma evacuation. Currently, it is used as a life-saving measure in deteriorating patients (Class IIb recommendation; level of evidence C). ${ }^{37}$ The ongoing SWITCH trial (NCT02258919) will hopefully shed more light on this procedure.

Minimally invasive procedures: In the setting of the above evidence, attempts have been made to mitigate the injury that can be caused by open surgery and craniotomy with a myriad of innovative, minimally invasive approaches. Prominent techniques include stereotactic-guided aspiration and thrombolysis, ultrasound-induced thrombolysis, image-guided stereotactic endoscopic aspiration, and stereotactic ICH underwater blood aspiration technique (SCUBA).

One of the first studies examined patients with ICH by randomizing them between medical management and minimally invasive, CT-guided craniopuncture therapy that involved aspiration of the hematoma, followed by injection of urokinase under pressure. ${ }^{83}$ The authors were able to show significant improvement in the clinical outcomes with a lower proportion of craniopuncture group being dependent at 90 days on the modified Rankin Scale (mRS). The
Minimally Invasive Surgery plus rt-PA for ICH Evacuation (MISTIE II) trial, a prospective randomized phase II trial results suggested a decrease in PHE and a trend toward improvement in clinical outcomes when compared with standard medical care. Image-guided cannula placement in the hematoma with clot aspiration followed by intra-clot administration of either of two doses of alteplase for up to nine doses and gravity-dependent drainage after every dose was attempted. ${ }^{84}$ Importantly, administration of the thrombolytic into the clot was found to be safe despite no improvement in the functional outcome at 180 days. Residual hematoma volume at the end of treatment seemed to correlate well with clinical outcomes. Based on this was the recently published MISTIE III trial, an open-labeled, blinded endpoint, phase 3 trial done across 78 centers that compared image-guided MISTIE treatment (1 mg alteplase every 8 hours for up to 9 doses) to standard medical care. Analysis performed on the modified intention-to-treat population revealed that there was no statistically significant difference between the groups of patients in achieving a good functional outcome, defined as patients who achieved an mRS score of 0 to 3 at 365 days. ${ }^{85}$ 
Exploratory analyses of the association of clot removal and functional outcome showed that the extent of clot removal was correlated with better outcomes. An as-treated analysis suggested that patients in whom the surgical aim of reduction in size of clot $\leq 15 \mathrm{~mL}$ was achieved had a benefit in mortality and functional outcome..$^{85}$ While the MISTIE trials have established that the process is safe, MISTIE as an intervention can still not be recommended for all ICH patients. We agree that the positive secondary outcome findings have to be treated as exploratory for reasons that include a selection bias that excluded clinically unstable patients with a poorer prognosis, as well as a bias in that clot removal was not randomized. The trial does invite future studies to explore the biological plausibility that reduction in mass effect and tissue injury caused by the presence of parenchymal blood with a MISTIE-like procedure may be very beneficial. A recent meta-analysis of four RCTs found that stereotactic aspiration of primary ICH resulted in reduced odds of death and dependency compared with traditional open techniques. ${ }^{86}$ Interestingly, there did not seem to be a significant difference in the risk of complications between the groups.

Basal ganglia and thalamic ICH result in IVH in about 50\% of patients ${ }^{87}$ which almost doubles the chance of poor outcomes ${ }^{88}$ Hydrocephalus is a frequent complication of IVH secondary to the block in CSF circulation. A meta-analysis has shown that IPH with IVH increases the risk of death from 20 to $51 \%{ }^{89}$ The CLEAR IVH trial showed safety of rt-PA injection into ventricles in the setting of IVH. ${ }^{90}$ The recent CLEAR III trial used thrombolytic therapy with catheter-assisted drainage to assess clot lysis in IVH and its impact on functional outcome at 180 days as compared to saline irrigation into ventricles. ${ }^{91}$ There was dose-dependent better resolution of clot, but the trial failed to show significant improvement in outcomes, and though the treatment group had lower case fatality, higher proportion of patients were left with severe disability. Also, routine and prolonged use of external ventricular drains in these situations increased the risk of ventriculitis.

Another interesting technique is image-guided endoscopic surgery for hematoma evacuation. The Intraoperative Stereotactic Computed Tomography-Guided Endoscopic Surgery trial was the first to assess the safety of the endoscopic procedure and outcomes at 6 months and 1 year, demonstrating a higher effective volume of hematoma removal and better neurological outcome among treated patients, though it had a small sample size. ${ }^{92}$ SCUBA is another neuroendoscopic technique that employs the Penumbra Apollo System (Penumbra Inc., Alameda, California, United States). An endoscopic sheath is inserted under stereotactic guidance into the hematoma cavity after which the Apollo system aspirates the clot. ${ }^{93}$ Following this, the hematoma cavity is infused with normal saline for visualization of the cavity and better evacuation. A study using this technique has shown a healthy evacuation average with low pre- and postprocedural bleeding. ${ }^{94}$ MiSPACE (minimally invasive subcortical parafascicular transsulcal access for clot evacuation) is a new technique that involves the transsulcal insertion of the BrainPath endoport (Nico Corp; Indianapolis, Indiana, United States) along a trajectory preplanned with MRI tractography, helping minimize the iatrogenic injury and improving the precision, ${ }^{95}$ with a recent multicenter trial providing safety data for this technique. ${ }^{96} \mathrm{~A}$ new trial-ENRICH (NCT02880878)is currently underway, further evaluating this modality. Ultrasound-guided thrombolysis where ultrasound energy is used to enhance clot lysis after rt-PA infusion is an option. A small study revealed better hematoma evacuation with sonothrombolysis when compared with catheter-based evacuation with rt-PA alone as attempted in the MISTIE and CLEAR trials. ${ }^{97}$

\section{Post-ICH Long-Term Therapeutic Decisions}

A frequent vexing question is the optimal time to restart antiplatelet medications or anticoagulation after recent ICH. In the absence of robust studies, we will defer to the guidelines, and time to the start of antiplatelet medications in those with a high risk of atherothrombosis, and anticoagulation in those at high risk for cardioembolic strokes (like those with prosthetic valves, intracardiac thrombus, and dilated cardiomyopathy $)^{98}$ with a prudent, patient-specific risk-benefit strategy, and optimize overall medical management. Being on these agents definitely increases the risk of late hemorrhage expansion as well as rebleeding. More recent retrospective data will need to be collected, especially for the DOACs in comparison to older agents such as warfarin.

\section{Conclusion}

ICH continues to have high morbidity and mortality. While recent research has centered on ICH stabilization, future directions in ICH care are bound to involve prevention and treatment of secondary neurologic injury with a clearer focus on long-term patient outcomes. More robust trials are necessary to tease out nuances of new treatment methods, while personalized intervention and management strategies are likely the future of ICH care.

\section{Conflict of Interest}

None declared.

\section{References}

1 Claude Hemphill J III, Lam A. Emergency neurological life support: intracerebral hemorrhage. Neurocrit Care 2017; 27(Suppl 1):89-101

2 Abegunde DO, Mathers CD, Adam T, Ortegon M, Strong K. The burden and costs of chronic diseases in low-income and middle-income countries. Lancet 2007;370(9603):1929-1938

3 Ikram MA, Wieberdink RG, Koudstaal PJ. International epidemiology of intracerebral hemorrhage. Curr Atheroscler Rep 2012;14(4):300-306

4 Strong K, Mathers C, Bonita R. Preventing stroke: saving lives around the world. Lancet Neurol 2007;6(2):182-187

5 Krishnamurthi RV, Moran AE, Forouzanfar MH, et al; Global Burden of Diseases, Injuries, and Risk Factors 2010 Study Stroke Expert Group. The global burden of hemorrhagic stroke: a summary of findings from the GBD 2010 study. Glob Heart 2014;9(1):101-106 
6 Hanley DF, Awad IA, Vespa PM, Martin NA, Zuccarello M. Hemorrhagic stroke: introduction. Stroke 2013;44(6 Suppl 1): S65-S66

7 van Asch CJ, Luitse MJ, Rinkel GJ, van der Tweel I, Algra A, Klijn CJ. Incidence, case fatality, and functional outcome of intracerebral haemorrhage over time, according to age, sex, and ethnic origin: a systematic review and meta-analysis. Lancet Neurol 2010;9(2):167-176

8 Ziai WC, Carhuapoma JR. Intracerebral hemorrhage. Continuum (Minneap, Minn) 2018;24(6):1603-1622

9 Falcone GJ, Biffi A, Devan WJ, et al; International Stroke Genetics Consortium. Burden of risk alleles for hypertension increases risk of intracerebral hemorrhage. Stroke 2012;43(11):2877-2883

10 O'Donnell MJ, Xavier D, Liu L, et al; INTERSTROKE investigators. Risk factors for ischaemic and intracerebral haemorrhagic stroke in 22 countries (the INTERSTROKE study): a case-control study. Lancet 2010;376(9735):112-123

11 Dye JA, Rees G, Yang I, Vespa PM, Martin NA, Vinters HV. Neuropathologic analysis of hematomas evacuated from patients with spontaneous intracerebral hemorrhage. Neuropathology 2014;34(3):253-260

12 Zhu XL, Chan MS, Poon WS. Spontaneous intracranial hemorrhage: which patients need diagnostic cerebral angiography? A prospective study of 206 cases and review of the literature. Stroke 1997;28(7):1406-1409

13 Biffi A, Greenberg SM. Cerebral amyloid angiopathy: a systematic review. J Clin Neurol 2011;7(1):1-9

14 McCarron MO, Nicoll JA. Cerebral amyloid angiopathy and thrombolysis-related intracerebral haemorrhage.Lancet Neurol 2004;3(8):484-492

15 Ellis RJ, Olichney JM, Thal LJ, et al. Cerebral amyloid angiopathy in the brains of patients with Alzheimer's disease: the CERAD experience, Part XV. Neurology 1996;46(6):1592-1596

16 Pezzini A, Grassi M, Paciaroni M, et al; Multicenter Study on Cerebral Hemorrhage in Italy (MUCH-Italy) Investigators. Antithrombotic medications and the etiology of intracerebral hemorrhage: MUCH-Italy. Neurology 2014;82(6):529-535

17 National Institute of Neurological Disorders and Stroke rt-PA Stroke Study Group. Tissue plasminogen activator for acute ischemic stroke. N Engl J Med 1995;333(24):1581-1587

18 Falcone GJ, Radmanesh F, Brouwers HB, et al; International Stroke Genetics Consortium. APOE $\varepsilon$ variants increase risk of warfarin-related intracerebral hemorrhage. Neurology 2014;83(13):1139-1146

19 Appelboom G, Bruce SS, Hickman ZL, et al. Volume-dependent effect of perihaematomal oedema on outcome for spontaneous intracerebral haemorrhages. J Neurol Neurosurg Psychiatry 2013;84(5):488-493

20 Naidech AM, Bernstein RA, Levasseur K, et al. Platelet activity and outcome after intracerebral hemorrhage. Ann Neurol 2009;65(3):352-356

21 Murthy SB, Moradiya Y, Dawson J, Lees KR, Hanley DF, Ziai WC; VISTA-ICH Collaborators. Perihematomal edema and functional outcomes in intracerebral hemorrhage: influence of hematoma volume and location. Stroke 2015;46(11):3088-3092

22 Venkatasubramanian C, Mlynash M, Finley-Caulfield A, et al. Natural history of perihematomal edema after intracerebral hemorrhage measured by serial magnetic resonance imaging. Stroke 2011;42(1):73-80

23 Arima $\mathrm{H}$, Wang JG, Huang $\mathrm{Y}$, et al; INTERACT Investigators. Significance of perihematomal edema in acute intracerebral hemorrhage: the INTERACT trial. Neurology 2009;73(23):1963-1968

24 Sansing LH, Kaznatcheeva EA, Perkins CJ, Komaroff E, Gutman FB, Newman GC. Edema after intracerebral hemorrhage: correlations with coagulation parameters and treatment. J Neurosurg 2003;98(5):985-992
25 Urday S, Beslow LA, Dai F, et al. Rate of perihematomal edema expansion predicts outcome after intracerebral hemorrhage. Crit Care Med 2016;44(4):790-797

26 Wu TY, Sharma G, Strbian D, et al. Natural history of perihematomal edema and impact on outcome after intracerebral hemorrhage. Stroke 2017;48(4):873-879

27 Lim-Hing K, Rincon F. Secondary hematoma expansion and perihemorrhagic edema after intracerebral hemorrhage: from bench work to practical aspects. Front Neurol 2017;8:74

28 Selim M, Norton C. Perihematomal edema: Implications for intracerebral hemorrhage research and therapeutic advances. J Neurosci Res 2018. 10.1002/jnr.24372

29 Qureshi AI, Hanel RA, Kirmani JF, Yahia AM, Hopkins LN. Cerebral blood flow changes associated with intracerebral hemorrhage. Neurosurg Clin N Am 2002;13(3):355-370

30 Gregoire SM, Charidimou A, Gadapa N, et al. Acute ischaemic brain lesions in intracerebral haemorrhage: multicentre cross-sectional magnetic resonance imaging study. Brain 2011;134(Pt 8):2376-2386

31 Nakagawa K, Serrador JM, LaRose SL, Sorond FA. Dynamic cerebral autoregulation after intracerebral hemorrhage: a case-control study. BMC Neurol 2011;11:108

32 Minhas JS, Panerai RB, Robinson TG. Feasibility of Improving Cerebral Autoregulation in Acute Intracerebral Haemorrhage (BREATHE-ICH) study: a protocol for an experimental interventional study. BMJ Open 2018;8(3):e020758

33 Prabhakaran S, Naidech AM. Ischemic brain injury after intracerebral hemorrhage: a critical review. Stroke 2012;43(8):2258-2263

34 Diringer MN, Edwards DF. Admission to a neurologic/neurosurgical intensive care unit is associated with reduced mortality rate after intracerebral hemorrhage. Crit Care Med 2001;29(3):635-640

35 Terént A, Asplund K, Farahmand B, et al; Riks-Stroke Collaboration. Stroke unit care revisited: who benefits the most? A cohort study of 105,043 patients in Riks-Stroke, the Swedish Stroke Register. J Neurol Neurosurg Psychiatry 2009;80(8):881-887

36 Wardlaw JM, Seymour J, Cairns J, Keir S, Lewis S, Sandercock P. Immediate computed tomography scanning of acute stroke is cost-effective and improves quality of life. Stroke 2004;35(11):2477-2483

37 Hemphill JC III, Greenberg SM, Anderson CS, et al; American Heart Association Stroke Council; Council on Cardiovascular and Stroke Nursing; Council on Clinical Cardiology. Guidelines for the management of spontaneous intracerebral hemorrhage: a guideline for healthcare professionals from the American Heart Association/American Stroke Association. Stroke 2015;46(7):2032-2060

38 Cucchiara B, Messe S, Sansing L, Kasner S, Lyden P; CHANT Investigators. Hematoma growth in oral anticoagulant related intracerebral hemorrhage. Stroke 2008;39(11):2993-2996

39 Brott T, Broderick J, Kothari R, et al. Early hemorrhage growth in patients with intracerebral hemorrhage. Stroke 1997;28(1):1-5

40 Hemphill JC III, Bonovich DC, Besmertis L, Manley GT, Johnston SC. The ICH score: a simple, reliable grading scale for intracerebral hemorrhage. Stroke 2001;32(4):891-897

41 Rost NS, Smith EE, Chang Y, et al. Prediction of functional outcome in patients with primary intracerebral hemorrhage: the FUNC score. Stroke 2008;39(8):2304-2309

42 Davis SM, Broderick J, Hennerici M, et al; Recombinant Activated Factor VII Intracerebral Hemorrhage Trial Investigators. Hematoma growth is a determinant of mortality and poor outcome after intracerebral hemorrhage. Neurology 2006;66(8):1175-1181

43 Delgado Almandoz JE, Schaefer PW, Goldstein JN, et al. Practical scoring system for the identification of patients with intracerebral hemorrhage at highest risk of harboring an underlying 
vascular etiology: the Secondary Intracerebral Hemorrhage Score. Am J Neuroradiol 2010;31(9):1653-1660

44 Halpin SF, Britton JA, Byrne JV, Clifton A, Hart G, Moore A. Prospective evaluation of cerebral angiography and computed tomography in cerebral haematoma. J Neurol Neurosurg Psychiatry 1994;57(10):1180-1186

45 Thompson AL, Kosior JC, Gladstone DJ, et al; PREDICTS/Sunnybrook ICH CTA Study Group. Defining the CT angiography 'spot sign' in primary intracerebral hemorrhage. Can J Neurol Sci 2009;36(4):456-461

46 Wada R, Aviv RI, Fox AJ, et al. CT angiography "spot sign" predicts hematoma expansion in acute intracerebral hemorrhage. Stroke 2007;38(4):1257-1262

47 Wang W, Zhou N, Wang C. Early-stage estimated value of blend sign on the prognosis of patients with intracerebral hemorrhage. BioMed Res Int 2018;2018:4509873

48 Pfleger MJ, Hardee EP, Contant CF Jr, Hayman LA. Sensitivity and specificity of fluid-blood levels for coagulopathy in acute intracerebral hematomas. Am J Neuroradiol 1994; 15(2):217-223

49 Rodriguez-Luna D, Piñeiro S, Rubiera M, et al. Impact of blood pressure changes and course on hematoma growth in acute intracerebral hemorrhage. Eur J Neurol 2013;20(9):1277-1283

50 Sakamoto Y, Koga M, Yamagami H, et al; SAMURAI Study Investigators. Systolic blood pressure after intravenous antihypertensive treatment and clinical outcomes in hyperacute intracerebral hemorrhage: the stroke acute management with urgent risk-factor assessment and improvement-intracerebral hemorrhage study. Stroke 2013;44(7):1846-1851

51 Anderson CS, Heeley E, Huang Y, et al; INTERACT2 Investigators. Rapid blood-pressure lowering in patients with acute intracerebral hemorrhage. N Engl J Med 2013;368(25):2355-2365

52 Qureshi AI, Palesch YY, Barsan WG, et al; ATACH-2 Trial Investigators and the Neurological Emergency Treatment Trials Network. Intensive blood-pressure lowering in patients with acute cerebral hemorrhage. N Engl J Med 2016;375(11):1033-1043

53 Steiner T, Al-Shahi Salman R, Beer R, et al; European Stroke Organisation. European Stroke Organisation (ESO) guidelines for the management of spontaneous intracerebral hemorrhage. Int J Stroke 2014;9(7):840-855

54 Mayer SA, Brun NC, Begtrup K, et al; FAST Trial Investigators. Efficacy and safety of recombinant activated factor VII for acute intracerebral hemorrhage. $\mathrm{N}$ Engl J Med 2008;358(20):2127-2137

55 Shakur H, Roberts I, Bautista R, et al; CRASH-2 trial collaborators. Effects of tranexamic acid on death, vascular occlusive events, and blood transfusion in trauma patients with significant haemorrhage (CRASH-2): a randomised, placebo-controlled trial. Lancet 2010;376(9734):23-32

56 Sprigg N, Flaherty K, Appleton JP, et al; TICH-2 Investigators. Tranexamic acid for hyperacute primary IntraCerebral Haemorrhage (TICH-2): an international randomised, placebocontrolled, phase 3 superiority trial. Lancet 2018;391(10135): $2107-2115$

57 Gómez-Outes A, Lagunar-Ruíz J, Terleira-Fernández AI, Calvo-Rojas G, Suárez-Gea ML, Vargas-Castrillón E. Causes of death in anticoagulated patients with atrial fibrillation. J Am Coll Cardiol 2016;68(23):2508-2521

58 Hanger HC, Fletcher VJ, Wilkinson TJ, Brown AJ, Frampton CM, Sainsbury R. Effect of aspirin and warfarin on early survival after intracerebral haemorrhage. J Neurol 2008;255(3):347-352

59 Steiner T, Poli S, Griebe M, et al. Fresh frozen plasma versus prothrombin complex concentrate in patients with intracranial haemorrhage related to vitamin $\mathrm{K}$ antagonists (INCH): a randomised trial. Lancet Neurol 2016;15(6):566-573

60 Pollack CV Jr, Reilly PA, Eikelboom J, et al. Idarucizumab for dabigatran reversal. N Engl J Med 2015;373(6):511-520
61 Soon CW, Kirsch IR, Connolly AJ, Kwong BY, Kim J. Eosinophil-rich acute febrile neutrophilic dermatosis in a patient with enteropathy-associated T-cell lymphoma, type 1 . Am J Dermatopathol 2016;38(9):704-708

62 Ansell JE, Bakhru SH, Laulicht BE, et al. Use of PER977 to reverse the anticoagulant effect of edoxaban. $\mathrm{N}$ Engl J Med 2014;371(22):2141-2142

63 Saloheimo P, Ahonen M, Juvela S, Pyhtinen J, Savolainen ER, Hillbom M. Regular aspirin-use preceding the onset of primary intracerebral hemorrhage is an independent predictor for death. Stroke 2006;37(1):129-133

64 Toyoda K, Okada Y, Minematsu K, et al. Antiplatelet therapy contributes to acute deterioration of intracerebral hemorrhage. Neurology 2005;65(7):1000-1004

65 Sansing LH, Messe SR, Cucchiara BL, Cohen SN, Lyden PD, Kasner SE; CHANT Investigators. Prior antiplatelet use does not affect hemorrhage growth or outcome after ICH. Neurology 2009;72(16):1397-1402

66 Moussouttas M, Malhotra R, Fernandez L, et al. Role of antiplatelet agents in hematoma expansion during the acute period of intracerebral hemorrhage. Neurocrit Care 2010;12(1):24-29

67 Baharoglu MI, Cordonnier C, Al-Shahi Salman R, et al; PATCH Investigators. Platelet transfusion versus standard care after acute stroke due to spontaneous cerebral haemorrhage associated with antiplatelet therapy (PATCH): a randomised, open-label, phase 3 trial. Lancet 2016;387 (10038):2605-2613

68 Frontera JA, Lewin JJ III, Rabinstein A, et al. Guideline for reversal of antithrombotics in intracranial hemorrhage: a statement for healthcare professionals from the Neurocritical Care Society and Society of Critical Care Medicine. Neurocrit Care 2016;24(1):6-46

69 Li X, Sun Z, Zhao W, et al. Effect of acetylsalicylic acid usage and platelet transfusion on postoperative hemorrhage and activities of daily living in patients with acute intracerebral hemorrhage. J Neurosurg 2013;118(1):94-103

70 Mannucci PM, Remuzzi G, Pusineri F, et al. Deamino-8-D-arginine vasopressin shortens the bleeding time in uremia. $\mathrm{N}$ Engl J Med 1983;308(1):8-12

71 Kim JH, Baek CH, Min JY, Kim JS, Kim SB, Kim H. Desmopressin improves platelet function in uremic patients taking antiplatelet agents who require emergent invasive procedures. Ann Hematol 2015;94(9):1457-1461

72 Naidech AM, Maas MB, Levasseur-Franklin KE, et al. Desmopressin improves platelet activity in acute intracerebral hemorrhage. Stroke 2014;45(8):2451-2453

73 Dennis M, Sandercock P, Reid J, Graham C, Forbes J, Murray G; CLOTS (Clots in Legs Or sTockings after Stroke) Trials Collaboration. Effectiveness of intermittent pneumatic compression in reduction of risk of deep vein thrombosis in patients who have had a stroke (CLOTS 3): a multicentre randomised controlled trial. Lancet 2013;382(9891):516-524

74 Morgenstern LB, Hemphill JC III, Anderson C, et al; American Heart Association Stroke Council and Council on Cardiovascular Nursing. Guidelines for the management of spontaneous intracerebral hemorrhage: a guideline for healthcare professionals from the American Heart Association/American Stroke Association. Stroke 2010;41(9):2108-2129

75 Brain Trauma Foundation; American Association of Neurological Surgeons, Congress of Neurological Surgeons, et al. Guidelines for the management of severe traumatic brain injury. VI. Indications for intracranial pressure monitoring. J Neurotrauma 2007;24(Suppl 1):S37-S44

76 Ziai WC, Melnychuk E, Thompson CB, Awad I, Lane K, Hanley DF. Occurrence and impact of intracranial pressure elevation during treatment of severe intraventricular hemorrhage. Crit Care Med 2012;40(5):1601-1608 
77 Da Pian R, Bazzan A, Pasqualin A. Surgical versus medical treatment of spontaneous posterior fossa haematomas: a cooperative study on 205 cases. Neurol Res 1984;6(3):145-151

78 Firsching $R$, Huber $M$, Frowein RA. Cerebellar haemorrhage: management and prognosis. Neurosurg Rev 1991;14(3):191-194

79 Hidalgo E, Asthana S, Nishio H, et al. Surgery for hilar cholangiocarcinoma: the Leeds experience. Eur J Surg Oncol 2008;34(7):787-794

80 Mendelow AD, Gregson BA, Fernandes HM, et al; STICH investigators. Early surgery versus initial conservative treatment in patients with spontaneous supratentorial intracerebral haematomas in the International Surgical Trial in Intracerebral Haemorrhage (STICH): a randomised trial. Lancet 2005;365(9457):387-397

81 Mendelow AD, Gregson BA, Rowan EN, Murray GD, Gholkar A, Mitchell PM; STICH II Investigators. Early surgery versus initial conservative treatment in patients with spontaneous supratentorial lobar intracerebral haematomas (STICH II): a randomised trial. Lancet 2013;382(9890):397-408

82 Gregson BA, Broderick JP, Auer LM, et al. Individual patient data subgroup meta-analysis of surgery for spontaneous supratentorial intracerebral hemorrhage. Stroke 2012;43(6):1496-1504

83 Wang WZ, Jiang B, Liu HM, et al. Minimally invasive craniopuncture therapy vs. conservative treatment for spontaneous intracerebral hemorrhage: results from a randomized clinical trial in China. Int J Stroke 2009;4(1):11-16

84 Hanley DF, Thompson RE, Muschelli J, et al; MISTIE Investigators. Safety and efficacy of minimally invasive surgery plus alteplase in intracerebral haemorrhage evacuation (MISTIE): a randomised, controlled, open-label, phase 2 trial. Lancet Neurol 2016;15(12):1228-1237

85 Hanley DF, Thompson RE, Rosenblum M, et al; MISTIE III Investigators. Efficacy and safety of minimally invasive surgery with thrombolysis in intracerebral haemorrhage evacuation (MISTIE III): a randomised, controlled, open-label, blinded endpoint phase 3 trial. Lancet 2019;393(10175):1021-1032

86 Wang JW, Li JP, Song YL, et al. Stereotactic aspiration versus craniotomy for primary intracerebral hemorrhage: a meta-analysis of randomized controlled trials. PLoS One 2014;9(9):e107614

87 Bhattathiri PS, Gregson B, Prasad KS, Mendelow AD; STICH Investigators. Intraventricular hemorrhage and hydrocephalus after spontaneous intracerebral hemorrhage: results from the STICH trial. Acta Neurochir Suppl (Wien) 2006;96:65-68

88 Hallevi H, Albright KC, Aronowski J, et al. Intraventricular hemorrhage: anatomic relationships and clinical implications. Neurology 2008;70(11):848-852
89 Gaberel T, Magheru C, Emery E. Management of non-traumatic intraventricular hemorrhage. Neurosurg Rev 2012;35(4): 485-494, discussion 494-495

90 Morgan T, Awad I, Keyl P, Lane K, Hanley D. Preliminary report of the clot lysis evaluating accelerated resolution of intraventricular hemorrhage (CLEAR-IVH) clinical trial. Acta Neurochir Suppl (Wien) 2008;105:217-220

91 Hanley DF, Lane K, McBee N, et al; CLEAR III Investigators. Thrombolytic removal of intraventricular haemorrhage in treatment of severe stroke: results of the randomised, multicentre, multiregion, placebo-controlled CLEAR III trial. Lancet 2017;389(10069):603-611

92 Vespa P, Hanley D, Betz J, et al; ICES Investigators. ICES (Intraoperative Stereotactic Computed Tomography-Guided Endoscopic Surgery) for brain hemorrhage: a multicenter randomized controlled trial. Stroke 2016;47(11):2749-2755

93 Fiorella D, Gutman F, Woo H, Arthur A, Aranguren R, Davis R. Minimally invasive evacuation of parenchymal and ventricular hemorrhage using the Apollo system with simultaneous neuronavigation, neuroendoscopy and active monitoring with cone beam CT. J Neurointerv Surg 2015;7(10):752-757

94 Kellner CP, Chartrain AG, Nistal DA, et al. The stereotactic intracerebral hemorrhage underwater blood aspiration (SCUBA) technique for minimally invasive endoscopic intracerebral hemorrhage evacuation. J Neurointerv Surg 2018;10(8):771-776

95 Day JD. Transsulcal parafascicular surgery using BrainPath ${ }^{\circledR}$ for subcortical lesions. Neurosurgery 2017;64(CN_suppl_1): 151-156

96 Labib MA, Shah M, Kassam AB, et al. The safety and feasibility of image-guided BrainPath-mediated transsulcul hematoma evacuation: a multicenter study. Neurosurgery 2017;80(4):515-524

97 Newell DW, Shah MM, Wilcox R, et al. Minimally invasive evacuation of spontaneous intracerebral hemorrhage using sonothrombolysis. J Neurosurg 2011;115(3):592-601

98 BroderickJ, Connolly S, Feldmann E, et al; American Heart Association/American Stroke Association Stroke Council; American Heart Association/American Stroke Association High Blood Pressure Research Council; Quality of Care and Outcomes in Research Interdisciplinary Working Group. Guidelines for the management of spontaneous intracerebral hemorrhage in adults: 2007 update: a guideline from the American Heart Association/American Stroke Association Stroke Council, High Blood Pressure Research Council, and the Quality of Care and Outcomes in Research Interdisciplinary Working Group. Circulation 2007;116(16):e391-e413 